\title{
Formative evaluation of sustainability in rural electrification programs from a management perspective: A case study from Venezuela
}

\author{
A. López-González ${ }^{1,2 *}$, B. Domenech ${ }^{1,3}$, L. Ferrer-Martí1 ${ }^{1,4}$ \\ ${ }^{1}$ Institute of Industrial and Control Engineering, Universitat Politècnica de Catalunya - BarcelonaTech (Spain) \\ ${ }^{2}$ Socioeconomic Center of Petroleum and Alternative Energies, Universidad del Zulia (Venezuela) \\ ${ }^{3}$ Department of Management, Universitat Politècnica de Catalunya - BarcelonaTech (Spain) \\ ${ }^{4}$ Department of Mechanical Engineering, Universitat Politècnica de Catalunya-BarcelonaTech (Spain)
}

Contact (*): Av. Diagonal 647, Pavilion F, Floor 0, 08028, Barcelona (Spain)

a.lopez@upc.edu ; (+34) 934.016.579

\begin{abstract}
Nowadays, around 1.2 billion people remain without access to electricity in rural areas of Africa, Asia and Latin America. In order to achieve universal access, a wide range of institutions must be involved in long-term rural electrification programs within a regional and national scope. In this context, the main objective of this research is to propose an evaluation methodology which aims to promote continual improvement of the programs underway, by undertaking the appropriate modifications in terms of their design and implementation. In this regard, a formative approach is sought, as the programs underway require from elements for continual improvement. In addition, a management perspective is also sought, as the results focus on program leaders for the implementation of suitable modifications, as and when needed. The proposed evaluation methodology considers 4 sustainability dimensions: environmental, technical, socioeconomic and institutional, in turn composed of 15 criteria that allow the design and implementation of the program to be analyzed in detail. The criteria are assessed by means of indicators dealing with the specific conditions of each program. As a case study, the Venezuelan program "Sowing Light" is taken as an empirical application of the proposed methodology. Launched in 2005, this program has been developed in three phases, reaching 900 rural communities to date, and is expected to benefit 2,020 more in the near future. Hence, the proposed evaluation methodology aims to provide useful results to compare RET-based electrification programs with conventional grid extension. Similarly, the methodology promotes continual improvement in favor of universal electricity access in rural communities in this country, as well as lessons learned that can be useful for the development of similar initiatives in other developing countries.
\end{abstract}

Keywords: rural electrification program; renewable energy; sustainability dimensions; formative evaluation; Venezuela 


\section{INTRODUCTION}

Currently, around 1.2 billion people remain without access to electricity in the less developed countries of the world [1]. Lack of electricity is one of the most significant barriers to overcoming poverty. In Latin America, 22 million people are without this service, mainly in countries such as Bolivia, Colombia, Guatemala, Haiti, Nicaragua and Peru [1]. This population tends to be scattered over large and barely accessible territories, so the possibilities for national grid extension are very limited [2]. In this regard, renewable energy technologies (RET) are suitable for such applications since the resources are widely distributed worldwide [3]. Indeed, between 2007 and 2016 the installed RET capacity for rural isolated areas has quintuplicated [4], supplying energy to almost 300 million people [5]. Of these systems, $86 \%$ can be found in developing countries in Africa, Asia and Latin America. Among the technologies used, photovoltaic (PV) has increased from 17\% of the total installed capacity in 2007 to nearly 50\% in 2016 [4], while the remaining RET have increased from $30 \%$ to $41 \%$ within the same period. According to the United Nations [6], this trend must be maintained or increased in coming years in order to attain universal access to adequate, modern and pollution-free energy in 2030.

In spite of the development of renewable energy for off-grid rural electrification, most private investors still consider such projects as unviable and not economically profitable, which has been an important limitation for large-scale RET-based rural electrification programs [7]. Consequently, many projects in developing countries have been undertaken by non-governmental organizations (NGO), with a limited impact on national indicators and rural electrification indexes (REI). For example, Peru, with the largest number of non-electrified houses in Latin America [8], is the country that has received most rural electrification projects from NGOs. However, only direct intervention by national government, between 2007 and 2013, led to a 60\% increase in the inter-annual REI, for the first time in the country's history [9]. In cases such as Brazil [10][11], Bolivia [12], Ecuador [13][14] and Venezuela [15], a similar trend can be observed. Actually, although close international technological cooperation is beneficial, the active participation of governments is essential for the effective design and implementation of RET-based rural electrification programs on a regional and national scale [16]. However, for governments and public institutions, the most significant barrier for the development of such initiatives is still the lack of confidence in RET [16].

Regarding the evaluation of rural electrification programs or groups of projects, Pereira et al. [17], studied initiatives from Brazil, China and India, concluding that the evaluation must be a mechanism included in the planning process in order to improve decision-making by generating information for deciding on realignment of the initial program objectives. Moreover, Slough et al. [11], made an evaluation of the "Light for all" program in Brazil. The work discusses the relationship between rural electrification and the Human Development Index. Terrapon-Pfaff et al. [18], evaluated 23 rural electrification projects in developing countries such as Cameroon, India, Mexico and Peru, among others. The proposed methodology is based on renewable energy sources, end-user needs, management models, finance and geographical issues, in order to determine the conditions influencing the projects' success or failure. Mainali et al. [19], introduced a method for evaluating the status of sustainability in rural electrification programs in developing countries, using a new-composite indicator: the energy sustainability index. Results were applied to Bangladesh, China, Ghana, India, South Africa and Sri-Lanka between 1990 and 2010. Finally, Urmee et al. [20], proposed a set of criteria for the evaluation of programs based on Solar Home Systems (SHS), considering a reverse approach for rural electrification: poverty alleviation and quality of life improvement come before the socioeconomic development. 
In order to overcome the barriers to RET-based rural electrification programs, ascertainable real data must be gathered, sustainability impacts measured and results presented in a clear and concise way to decision-makers in the field. However, van de Walle et al. [21] conclude that few studies have been published about the empirical evaluations of the impact of electricity access in its different dimensions. In this regard, evaluation methodologies must be clearly distinguishable from those programs used for urban, commercial and/or industrial electrification [22]. The main difference is that rural electrification must be focussed on poverty alleviation and the improvement of end-user daily life quality [20]. According to Zommers [23], the objectives of rural electrification programs can be grouped into four categories: economic, social, political and environmental. In practice, some objectives are simultaneously attained and are interrelated, thus reducing the groups to: socioeconomic, institutional or political and environmental. In fact, these objectives arise from the examination of sustainability in different dimensions, according to the first estimations of that concept [19]. For example, sustainability evaluation methodologies such as Ilskog's [24] consider five dimensions: technical, economic, ethic-social, environmental and institutional. Other authors such as Yadoo et al. [25] and Lillo et al. [26] have based their proposals on similar approaches. Therefore, considering the contributions of Zommers [23] and Ilskog [24], this paper proposes 4 dimensions for the evaluation of sustainability in rural electrification programs: environmental, technical, socioeconomic and institutional.

Program evaluations must provide objective results and synthesize the lessons learned in order to promote continual development of the initiatives underway, providing a useful perspective for decision-makers in order to improve the programs by implementing the appropriate measures on time [16]. Regarding the purpose, two different types of evaluation can be distinguished [17]: summative and formative. Summative evaluations basically aim to determine whether a program must continue or should be stopped, depending on whether the expected effect on electrification indexes is occurring or not [27]. For their part, formative evaluations do not focus on questioning the programs' appropriateness but on promoting continual improvement mechanisms. Regarding the perspective, evaluations can have an accountability or management approach [28]. The accountability perspective is useful for those who approve public funding for programs. In exchange, the management perspective allows information to be provided quickly enough for program leaders to be able to undertake the appropriate modifications as and when required.

In this context, the research objective is to propose an evaluation methodology of RET-based rural electrification programs, which assesses sustainability from four proposed dimensions (environmental, technical, socioeconomic and institutional) with a formative purpose and a management perspective. Hence, a comprehensive framework is provided for the continual improvement of such programs. Not many formative evaluations of rural electrification programs have been found in the literature. Among the few examples, an independent advisory board of the United Nations analyzed the "Sustainable Energy for All (SE4All)" program. This evaluation aimed to promote improvements in the design and implementation of the program, helping to understand what had worked and why, from the concept basis [29]. However, no other background on formative assessments has been found within the reviewed literature in the context of rural electrification programs. Apart from rural electrification, this approach has been used to assess electricity distribution utilities [30], public work programs in the context of chronic poverty (in Malawi, for example) [31] and other governmental programs [32] in different areas of development [33]. Therefore, the main objective of this research is to propose a formative methodology with a management perspective, particularly designed for the sustainability assessment of rural electrification programs. As an application and illustration, the methodology 
is used in the Venezuelan "Sowing Light" program. Indeed, other assessment methodologies have been developed in the literature, (i.e. Ilskog [34], Yadoo et al. [25], Lillo et al. [26] and Zomers [23]), although they are based on different approaches and their scope of application is more limited.

With the purpose of easing the development of formative evaluations of RET-based rural electrification programs with a management perspective, a structured methodological approach is developed in this work. The evaluation of the four dimensions of sustainability (environmental, technical, socioeconomic and institutional) is performed by means of a set of criteria sufficiently robust to be replicated, practically and efficiently, in other cultural, institutional and socioeconomic contexts [35]. The evaluation criteria have been defined considering the formative approach and the management perspective, in order to ensure the results provide valid elements for clearly identifying improvement mechanisms, in the design and/or the implementation of the program, as well as to overcome possible institutional barriers [33]. The evaluation methodology is illustrated and validated through its application to the Venezuelan "Sembrando Luz" program ("Sowing Light") [36]. This program was launched in 2005 and since then 900 rural communities have benefited and 2,020 more will be reached in the coming years. The evaluation focusses on the period from 2005 to 2013 and the assessment of each criterion from each sustainability dimension is made by means of indicators defined according to the socioeconomic context of the program. For this purpose, 22 beneficiary communities were visited in the states of Bolívar, Falcón, Mérida and Zulia. A total of 151 interviews were held with end-users, in addition to 26 non-structured but wider surveys of community operators and leaders as well as expert technicians. Additionally, data from the National Institute for Statistics from Venezuela was consulted [37]. The surveys and interviews have made it possible to know, from the end-users' perspective, both their acceptance of technologies and their satisfaction with the electricity service. Also, using the INE database, the local, regional and national impact of the program has been evaluated, considering the 4 proposed dimensions for sustainability assessment.

The remainder of the paper is organized as follows. In Section 2, the Venezuelan "Sowing Light" program is described, detailing the three implementation phases throughout the evaluated period as well as the management model and the implementation mechanisms. In Section 3, the proposed evaluation methodology is presented, defining the criteria included within each evaluation dimension. In Section 4, the results of applying the methodology to the "Sowing Light" program are shown; explaining how each criterion from each evaluation dimension is assessed by means of some previously defined indicators. In Section 5, the results are discussed, highlighting the relationships between criteria and dimensions. Moreover, a comparison between RET-based electrification projects and conventional electrification through grid extension, considering the four sustainability dimensions is carried out. Finally, in Section 6, the main conclusions of this investigation are summarized.

\section{RURAL ELECTRIFICATION PROGRAM "SOWING LIGHT"}

Venezuela has grown from an electrification rate of $96.77 \%$ in 2001 to $98.89 \%$ in 2011 and more than $99 \%$ in 2013 [38], using three different strategies:

- National grid expansion, carried out by the electricity utility company (ESC) [39].

- Installation of diesel-based energy systems (“Energy Revolution” program), partially carried out by the ESC and other government institutions. 
- Installation of RET-based energy systems ("Sowing Light" program), carried out by the Autonomous Authority for Rural Electrification (AARE) [39].

This work focusses on the evaluation of the "Sowing Light" program [15], launched in 2005 and developed by the Foundation for the Development of the Electricity Service (Fundelec) [40], assuming the AARE function in terms of RET-based projects. Between 2005 and 2013 the program has benefited nearly 142,000 people distributed throughout 900 rural communities [36], which represents $7 \%$ of the new electricity connections in Venezuela during that period [41]. The program is particularly important among indigenous population in Venezuela, which are a small minority usually located in dispersed rural settlements with low access to education, health and information services, negatively influencing their socioeconomic development [37]. Indeed, the indigenous population in rural Venezuela has historically been established in scattered settlements, living in small shacks ("ranchos"), as a consequence of their semi-nomadic lifestyle [42]. On average there are 6 people per house, with very small energy needs, in accordance with their traditional customs and habits. Therefore, off-grid RET-based electrification is particularly relevant for this population. In the following sections, a general overview is provided of the most significant aspects concerning the design, implementation and management model of the "Sowing Light" program.

\subsection{Program design}

The design of the program is adapted to the energy policy established by the Regulatory Entity (RE), in this case the Electrical Energy Ministry, which aims to expand electricity access through adequate RET depending on the availability of Distributed Energy Resources (DER) in each community. This energy policy defines the design and implementation requirements for the "Sowing Light" program, through the following objectives [43]:

- Include rural indigenous and frontier communities into the basic services coverage with a reliable and adequate access level.

- Support previously excluded communities, through the supply of electricity, and national government education and health programs.

- Increase the income levels in communities, through the supply of electricity, by increasing efficiency in productive activities, in order to reduce poverty levels.

- Strengthen sustainable development projects linked to the territory and/or municipal, state or national government funding.

- Promote sustainable development in benefited communities.

Although the "Sowing Light" program is designed by the AARE (Fundelec), it must be discussed and finally approved by the three institutions responsible for the electricity service in the country (AARE, ESC and RE). The ESC participation means that those non-electrified communities that will be served by the national grid extension or diesel-based energy systems can be distinguished from those requiring RET-based projects. The AARE is responsible for ascertaining the electricity needs in such communities. Meanwhile, the RE is the direct representative of the national energy plans and policies. All the projects included in the "Sowing Light" program are coordinated by the AARE and the Community Councils (CC), directly representing each benefited community. Finally, the AARE is also in charge of the design and adaptation of the electrification technologies. In all the communities, $2.0 \mathrm{kWh} /$ day energy demand is considered for houses, 3.7 $\mathrm{kWh} /$ day for health centres and $7.7 \mathrm{kWh} /$ day for schools. The estimation of the average daily consumption was carried out by Fundelec (Ministry of Electric Energy of Venezuela). The 
estimation was based on historical data obtained during the national censuses carried out by the National Institute for Statistics of Venezuela (INE), in previously electrified rural houses, health centres and schools. Moreover, Fundelec carried out surveys in rural areas to be electrified in order to profile the houses and inhabitants [43]. Thus, a typical list of rural house appliances and their use was generated (Table 1), while the corresponding to rural schools and rural health centres is obtained from weighted average measurements of electricity consumption, in this type of facilities.

Table 1. Daily average consumption estimation procedure is based on Fundelec surveys on rural houses all over Venezuela and result is a $2 \mathrm{kWh} / \mathrm{d}$

\begin{tabular}{|c|c|c|c|}
\hline House appliances & Quantity & $\begin{array}{l}\text { Daily use } \\
\text { (Hours) }\end{array}$ & $\begin{array}{c}\text { Average daily } \\
\text { consumption (Wh) }\end{array}$ \\
\hline T.V & 1 & 5 & 400 \\
\hline Fluorescent light bulbs & 5 & 5 & 275 \\
\hline Electronic devices & 1 & 5 & 125 \\
\hline Freezer & 1 & 24 & $1200^{*}$ \\
\hline \multicolumn{3}{|c|}{ Total average daily consumption (Wh) } & 2000 (2 kWh) \\
\hline
\end{tabular}

* Based on an average consumption of $438 \mathrm{kWh} /$ year, which corresponds to a consumption of 1.2 $\mathrm{kWh} /$ day. In none of the cases, the demand can exceed $400 \mathrm{~W}$.

\subsection{Program implementation: development phases}

In order to achieve the "Sowing Light" program objectives, the institutional organization of the AARE and the RE is required on a national level. The program implementation is supervised by the RE, which is also responsible for combining with the education, health and rural development institutions of the national government in order to support the sustainable development of benefited communities. The "Sowing Light" program has been developed in three execution phases, using a specific strategy and RET in each, as described next.

\section{First phase: RET for community infrastructures and drinking water.}

In 2005 the first program phase started and $850 \mathrm{PV}$ systems were installed $(810 \times 1,200 \mathrm{Wp}$ and $40 \times 3,840 \mathrm{Wp}$ ) for the electrification of social canteens, health centres, community centres, schools and telecommunication centres (Figure 1.1), among other social objectives. A total capacity of 1,125.6 kWp was installed, benefiting almost 500 communities and around 130,000 people. In addition, $162 \mathrm{PV}$ panels were installed to supply water purification systems, 54 for water desalination systems and 78 for water pumping systems from deep wells [43]. A total capacity of $341.1 \mathrm{kWp}$ was installed for these technologies [44].

\section{Second phase: Solar Home Systems (SHS).}

In 2007 the second phase started and 445 SHS of $300 \mathrm{Wp}$ and 1726 of $600 \mathrm{Wp}$ were installed. Around 10,000 people benefited, spread over more than 100 communities (Figure 1.2), with the total installed capacity being $1,169.1 \mathrm{kWp}$. In some cases, the $600 \mathrm{Wp}$ SHS have been used to supply two or more houses, especially in indigenous communities. 


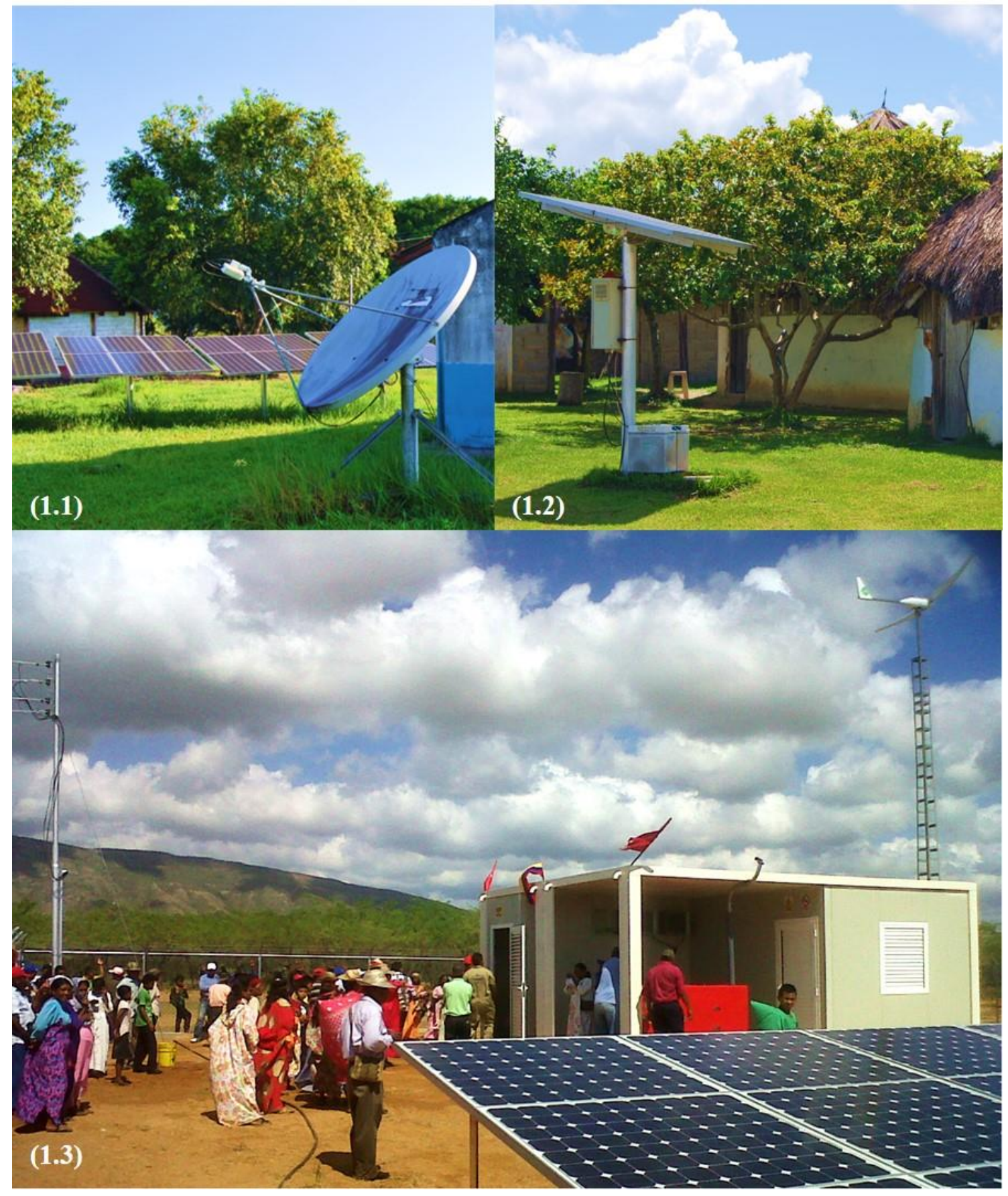

Figure 1. Generation systems used in the 3 phases of the "Sowing Light" program, in Venezuela. (1.1) school PV system in Mapaurí (Gran Sabana, Bolívar State), phase 1; (1.2) SHS in Arapán (Gran Sabana, Bolívar State), phase 2; (1.3) HMG in Wososopo (La Guajira, Zulia State), phase 3. 


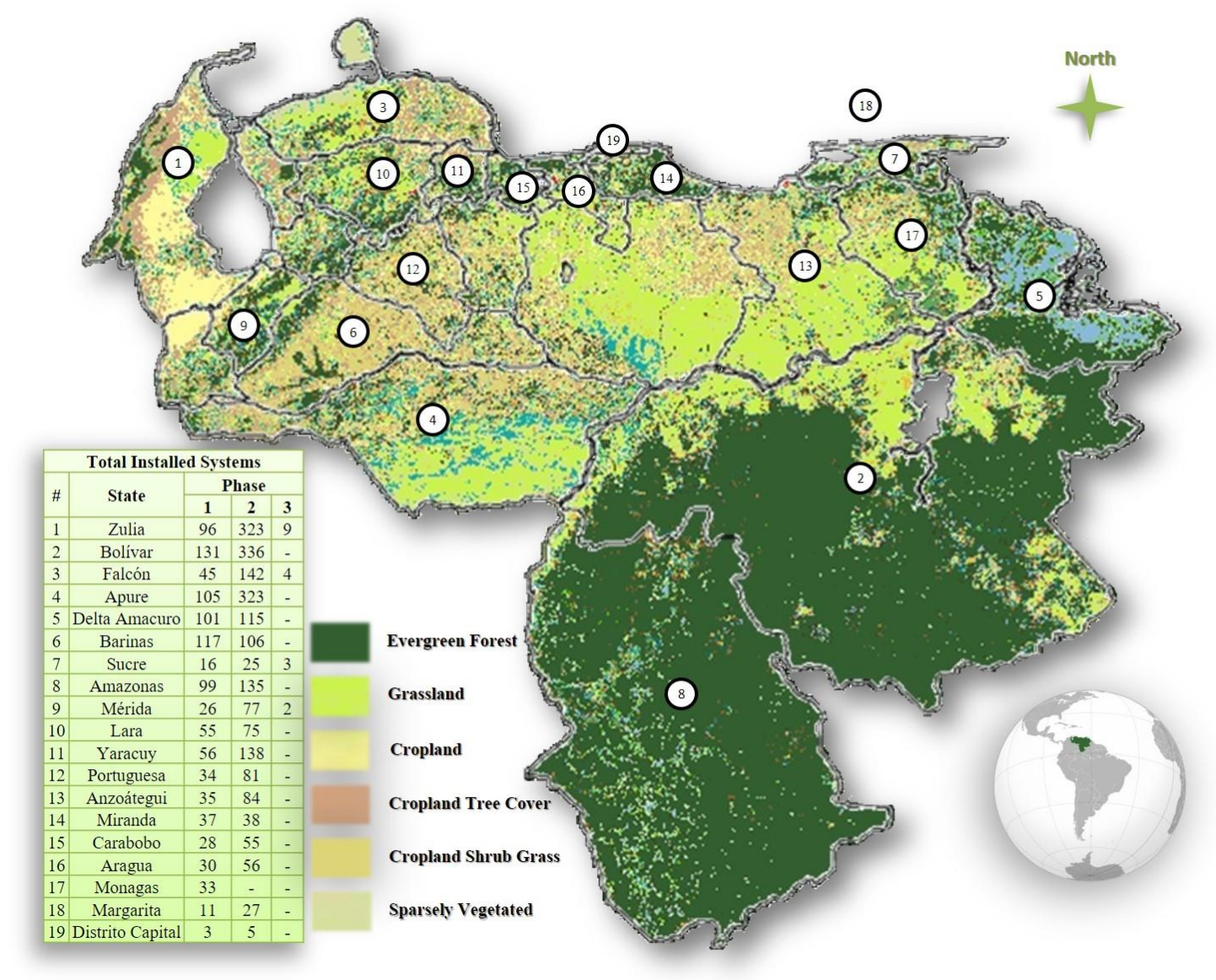

Figure 2. National land coverage map [45] and installed systems by state and phase within the RET-based rural electrification program "Sowing Light" [44], in Venezuela

\section{Third phase: Hybrid Microgrids (HMG) and House-sized Wind Turbines (HWT)}

In 2009 the third program phase was launched, which involved installing HMG including one or two $3 \mathrm{~kW}$ and/or $6 \mathrm{~kW}$ wind turbines, PV panels, batteries and a backup diesel generator [46], using power electronics conversion and control systems to synchronize equipment. HMG are grouped into four categories, according to their capacity, depending on whether they can supply communities of up to 10, 20, 30 and 40 houses. Since the phase started, 18 HMG have been installed, providing electricity to 300 houses and 1,800 people. Figure 1.3 shows a 20-house capacity system for the indigenous community of Wososopo (La Guajira, Zulia state). In 2012, installation of $1.5 \mathrm{~kW}$ HWT started in Falcón and Mérida, with a total of 30 houses currently recorded as electrified using this technology [47].

Most of the communities benefited by the three phases of the program are located in the southern, north-western and north-eastern territories of Venezuela, the region's most lacking basic services (Figure 2). Currently, the national government is expecting to reach 2,020 additional villages through the installation of 3,872 PV systems for community infrastructures (phase 1), 15,713 SHS (phase 2) and 149 HMG (phase 3) [48]. In order to achieve this goal, Venezuela started manufacturing PV panels and wind turbines in 2013, specifically in Falcón state [47]. 


\subsection{Program implementation: management model}

The "Sowing Light" program is based on a Participatory Management Model (PMM) scheme, that can be classified within the third level of the Arnstein participation scale [49]. The called "Arnstein's Ladder", defines three levels of community participation: 1) non-participation, 2) tokenism and 3) citizen empowerment. First, non-participation implies allowing companies or AARE to assume a public commitment without involving users. Second, tokenism implies that information about the projects is provided in order to reach a not binding and very limited users' opinion. Finally, third, citizen empowerment is a participation scheme including responsibility delegation and the ability of users to control the service they are receiving [50]. The proposed participation scheme includes joint responsibility of program developers (mainly the AARE) and end-users, so that they all assume the maintenance and management activities of the electrification systems, and beneficiaries can then control the service they are receiving. In this regard, the contribution that end-users may provide to the project development is recognized, in both program design and implementation [49]. Thus, end-users have negotiation capacity and management power to take decisions about the electrification systems [8]. Similar management model approaches have been implemented in other Andean countries, such as Bolivia and Ecuador [51]. Next, the PMM scheme is detailed (Figure 3).

On a national level, the Autonomous Authority for Rural Electrification (AARE), as program coordinator, promotes the technical strengthening at local community level by training Community Operators (COs), nominated by CC. Such councils are the direct representation of end-users and gather technical complaints about the electrification systems through User Assemblies (UA). Thus, the joint responsibility of AARE-communities is established for systems maintenance, aiming to achieve a medium and long-term self-management model [52]. End-users are responsible for defining the electricity tariff to fund the effective maintenance of RET-based facilities, which may vary monthly depending on the costs to be faced. To do so, UA are periodically organized and decisions are requested from the CC. Such decisions also include the disconnection of houses for non-payment, as well as the preparation of a schedule for planned supply interruptions due to maintenance activities, diesel savings or to prevent deep discharges of batteries. It should be noted that this scheme is valid for community infrastructures (phase 1) and HMG (phase 3), while for SHS (phase 2), no tariff is paid and COs are avoided, as minor maintenance activities are carried out by the users themselves.

Simultaneously, the AARE supervises several regional technician teams, organized as Service and Maintenance Units (SMU), which constitute a network of mobile workshops for the preventive, predictive and corrective maintenance of RET-based facilities. In the case of major repairs or replacements, the damaged equipment is transported to the Central Workshop (CW). In addition, the SMU from each region is responsible for continuous training of COs from the communities included in the area, thus ensuring the project's effectiveness and sustainability. In the case of an equipment breakdown beyond the COs repair skills, it is communicated to the corresponding regional SMU. If there is no response, the $\mathrm{CC}$ presents a complaint to the regional representation of the RE, which will raise it at a national level and, if necessary, apply administrative penalties to the AARE.

In short, under the PMM approach, at a local level, minor maintenance activities are carried out by the $\mathrm{CO}$, electricity tariffs are established by the UA and systems are globally managed by the CC. At a regional level, bigger maintenance activities are addressed, through communication between the COs and the corresponding SMU or, otherwise, between the CC and the RE. At a 
national level, major maintenance activities are performed at the $\mathrm{CW}$ under the supervision of the AARE.

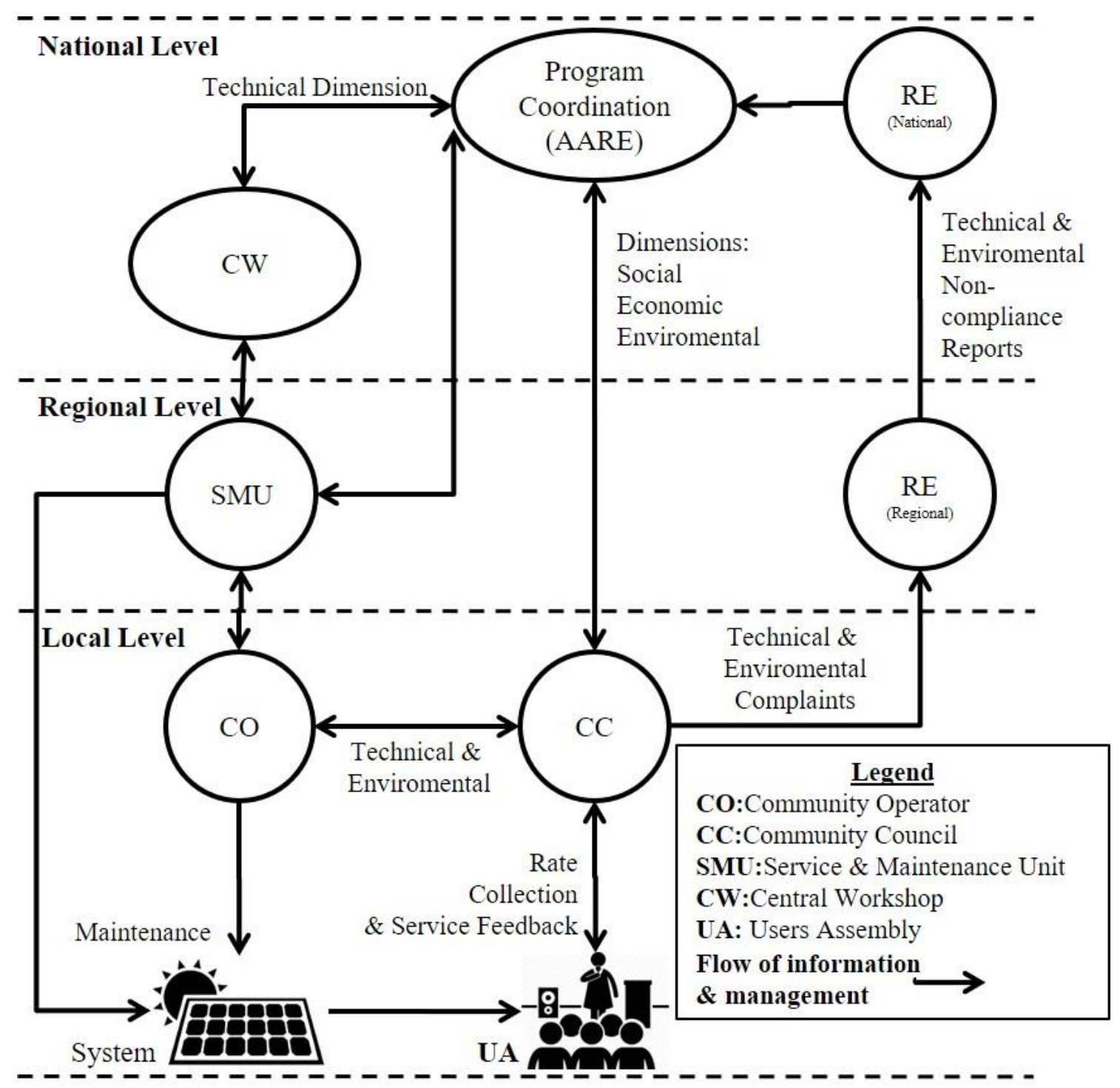

Figure 3. Participatory Management Model (PMM) used for the RET-based rural electrification program "Sowing Light", in Venezuela

\section{Proposed evaluation Methodology}

The construction of the proposed evaluation methodology is theoretically based on some assumptions of programs and public policies evaluation described in the literature. For example, the terms "formative" or "summative" were adopted by Scriven in 1967 [53] in his discussion on the evaluation of educational programs. Since then, these terms have been used to refer to evaluations with different purposes [27]. Additionally, experiences like the evaluation of the recovery of public works in Blantyre City, Malawi, were taken into account for the conceptual framework of our proposed dimensions [31]. Formative evaluations provide a comprehensive conceptual framework to assist in the systematic analysis of the implementation process and the results of a program. Through the literature review, it may be concluded that formative evaluation is the most suitable approach for the proposed methodology, since it allows to improve the performance considering even when summative purposes are included [32]. Other references have 
been used for the conceptual framework of the proposed methodology, among them: Schoster et al. [54] and Brown et al. [55].

Regarding the perspective, the research from Eleanor in 1978 [28] was particularly relevant for the proposed methodology definition. The management perspective provides a wide scope on the program, both at the design and implementation stages in terms of achievements and failures. Most developing countries make their Electrical Service Companies (ESC) and governments to work together in rural electrification widespread programs. Therefore, instead of technical, particular or specialized perspective, a management perspective is priorly needed. The most important improvement needed is policy-makers, officials and public institutions to understand RET-based rural electrification programs from all their dimensions and stages. Thus, a management perspective is required since governments and public or private ESC directives are the main stakeholders in developing countries energy access programs [16].

In this section, our proposed sustainability evaluation methodology of RET-based rural electrification programs is detailed. As introduced in Section 1, the methodology has a formative purpose and a management perspective. In terms of the formative purpose, a set of 15 evaluation criteria are defined in order to assess the design and implementation of the program. Each criterion is related to a specific dimension considered for sustainability: environmental, technical, socioeconomic and institutional. Figure 4 shows the proposed approach for the evaluation methodology, which is now explained.

In particular, the AARE carries out the design of the program, according to the objectives defined by the RE. Consequently, the final results of the program must be consistent with the objectives. Hence, the formative purpose of the evaluation of the program design, through the corresponding criteria, aims to identify those elements not responding to the expected objectives so that the decision-makers (the AARE) can carry out improvements.

Otherwise, the AARE implements the program and all the included projects, producing two different results: final and intermediate. Final results are those that directly reflect the accomplishment of the program objectives, while intermediate results represent previous conditions to the accomplishment of one or more objectives. Consequently, the RE and the AARE must monitor the program by means of the final results. However, these results do not allow those aspects requiring improvement to be clearly distinguished.

Therefore, the proposed evaluation methodology, with a formative purpose and a management perspective, is based on criteria that allow both the final and intermediate results to be assessed. In this context, intermediate results show how the AARE has implemented (or not) the models and mechanisms that will finally determine the final results and the accomplishment of the program objectives. Figure 5 shows the evaluation criteria according to the sustainability dimension where they are classified, as well as whether they belong to the evaluation of the design or the implementation of the RET-based rural electrification program, in terms of intermediate or final results. Note that the criteria have been selected to be easily replicable in other social, economic and technological contexts.

In short, the criteria providing information about the design are those that can be modified without changing the program objectives. For their part, the criteria providing information about implementation can identify aspects to be improved in terms of the final or intermediate results of the program. The final results are directly linked to the quantification of advances in the program objectives [31]. Meanwhile, the intermediate results are indirectly linked to the program 
objectives as they do not quantify their accomplishment. For example, the Technological change (E-2) is a criterion for the evaluation of intermediate results, since it is not a program objective but directly impacts on the mitigation of emissions, which is a final result included within the objectives. However, the technological change will occur if the design of the project is adequate. Therefore, (E-2) is a criterion to evaluate both the design and implementation of the projects included within the program. In the following sections, the criteria corresponding to each sustainability dimension are described.

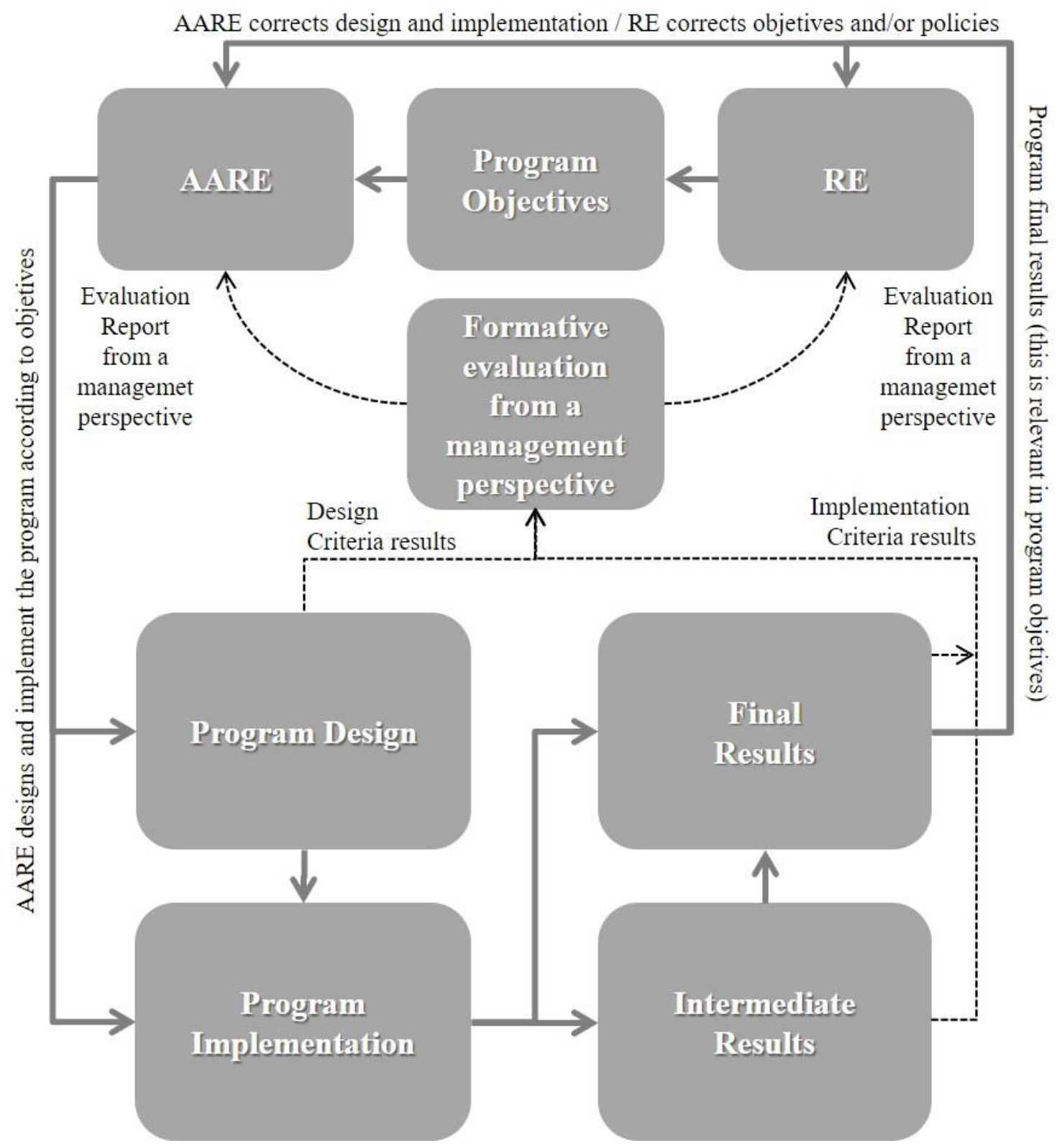

Figure 4. Proposed methodology for the formative evaluation of sustainability, from a management perspective, for the design and implementation of RET-based rural electrification programs 


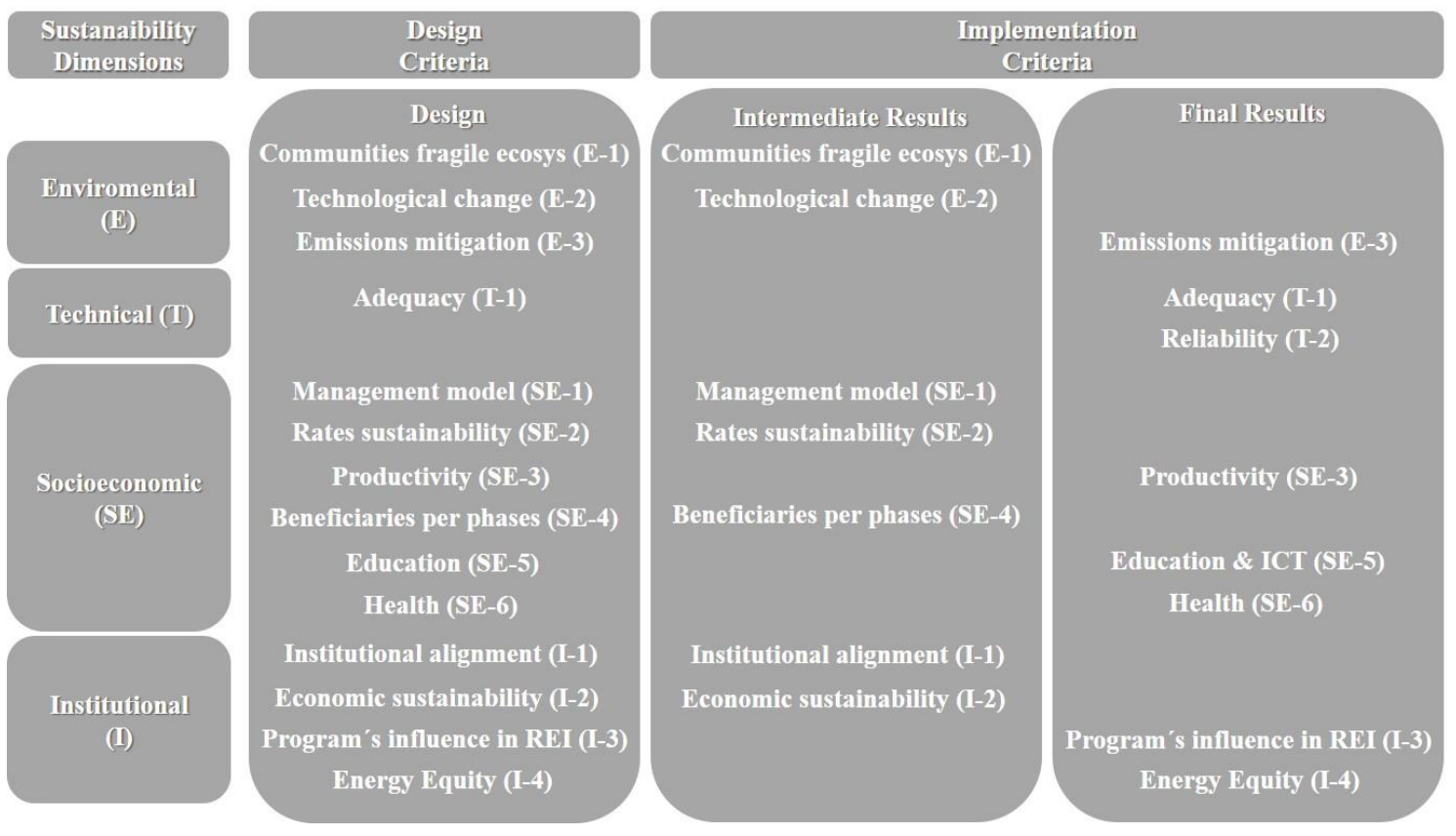

Figure 5. Proposed sustainability evaluation dimensions and criteria according to program stages

\subsection{Environmental dimension}

This dimension is related to the activities attached to the projects that have an influence on the local ecosystems and the natural resources of the electrified location [24]. Greenhouse gas emissions factors must be considered both for projects and programs, as well as the impact of the new technology on the biomass for cooking and illumination purposes and the efficient use of primary energy resources [6]. This has the effect of reducing pollution inside the houses (local level), the community surroundings (regional level) and the atmosphere (national level). In order to assess the environmental dimension of rural electrification programs, three criteria are proposed:

Communities fragile ecosystem (E-1): this criterion is used to assess the hierarchical organization and prioritization that the program makes about project assignment in communities located in fragile and vulnerable ecosystems. The criterion allows the program design to be evaluated and, in terms of implementation, produces intermediate results.

Technological change (E-2): the change in energy technologies within the electrified community is assessed by means of this criterion, in favour of the reduction of equivalent $\mathrm{CO}_{2}$ emissions [56]. The criterion allows the evaluation of both the program design and its capacity to promote an improvement in energy technology efficiency. It also produces intermediate results as the technological change is not an objective in itself but has an influence on them.

Emissions mitigation ( $E-3$ ): this criterion quantitatively measures the volume of avoided emissions (equivalent $\mathrm{CO} 2$ tones) from the levels of technological change and emission intensity or emission factor $\left(\mathrm{kgCO}_{2} / \mathrm{kWh}\right)$ [57]. The criterion allows the design to be evaluated and provides final results, as the mitigation of emissions is a determining factor for the accomplishment of the fifth objective of the program (Section 2.1). 


\subsection{Technical dimension}

The technical dimension is related to the accomplishment of global access to reliable and modern energy for all, as defined in the seventh objective of the 2030 agenda [6]. In this regard, the two criteria considered are directly related to each other. The adequacy evaluates how effective energy access is in supplying the energy requirements of the benefited population. It depends on the reliability criterion, as an adequate supply must be continuous, reliable and of a standardized quality [58]. Next, the two criteria are described:

Adequacy (T-1): the energy availability through the electrification system is compared to the minimum adequacy threshold for the context of the program [3]. This threshold may be different in each region and has to be defined from typical energy requirements [59]. This criterion is relevant for the evaluation of the design and provides final results, as it is decisive in accomplishing the first objective of the program (Section 2.1).

Reliability (T-2): the frequency of failures and their duration are assessed. This task can be performed through historical records or through end-user perceptions [60]. In the latter case, it is usually influenced by the local context of communities. The criterion allows the final results to be evaluated, as reliability is decisive for the accomplishment of the first objective of the program (Section 2.1).

\subsection{Socioeconomic dimension}

The economic and social dimensions are considered as a single aspect for sustainable development [61]. The objectives of any rural electrification program have a socioeconomic purpose, as electricity is understood as a means for development [20]. First, energy must be affordable for end-users [6], so sufficient productivity levels must be reached to defray the cost of electricity facilities in a sustainable manner, under an efficient management model. The management model, rates sustainability and productivity are the economic aspects; while beneficiaries per phase, education and health are the social aspects that will have an influence on the medium and long term improvements. Next, the six criteria are described:

Management model (SE-1): the efficiency of the management model implemented is assessed in terms of end-user satisfaction with the electricity rate, the maintenance and the general organization of community electrification systems (Section 2.3) [62]. The management model starts with the program design and provides intermediate results, as it has only an indirect influence in achieving the program objectives.

Rates sustainability (SE-2): electricity rates are assessed in order to be affordable and, at the same time, sufficient to maintain systems operational over the long term. The rates are defined throughout the design and provide intermediate results, as they only have an indirect influence on the attainment of the program objectives.

Productivity (SE-3): the increase in end-user income levels is evaluated as a result of electricity access in their houses and/or communities. The productivity can be understood as the improvement in family or community incomes thanks to productive activities. In this regard, potential improvements in productivity from the program design must be considered, as it provides decisive final results in the accomplishment of the third and fourth objectives of the program (Section 2.1). 
Beneficiaries per phase (SE-4): end-users can notice the direct or indirect benefit of an electrification system. Consequently, three scopes for this criterion are considered [3]: electrification of community infrastructures for public services; electrification of productive centers, companies and farms in the surroundings, and electrification of houses. The number of beneficiaries per system of installed capacity must be evaluated in each project, depending on its scope. The program must be designed to consider a larger number of beneficiaries at the lowest economic and logistic levels, so intermediate results are provided here.

Education (SE-5): the improvement in education quality and literacy levels [63] as a result of electrification are assessed. The program must be designed to consider the promotion of better education levels, which are significant in accomplishing the second and fifth objectives of the program (Section 2.1), so final results are provided.

Health (SE-6): the improvement of health conditions, as a result of electrification within houses and the surrounding community, are evaluated. This is relevant for the evaluation of the design and provides final results decisive for the second and fifth objectives of the program (Section 2.1).

\subsection{Institutional dimension}

Rural electrification sustainability assessment is usually focused on technical or economical dimensions, omitting the institutional one. According to Gollwitzer et al. [64], this traditional assessment framework contributes to the high failure rates in this kind of projects. The institutional dimension considers the way in which institutions, companies, communities or any other entity involved in the program interact to reach a set of predefined goals based on international agreements, ethical statements or legal assumptions. The global failure rate in rural electrification projects, estimated in 50-100\%, is highly influenced by institutional barriers and wrong management models [64]. Therefore, interaction must fluid and harmonious between the different institutions involved: ESC, AARE and RE [65], as well as education and health rural authorities. Sergi et al. [64], claim that although international development agencies have provided financial support to some developing countries, their institutions continue to favor ongrid and grid extension activities since some institutional challenges need to be overcome. In this sense, an institutional alignment must be achieved to overcome the institutional barriers that usually arise in these programs and projects due to financial limitations, management models and managerial training lack [66]. In this regard, an indicator as equity is related to overcoming the energy trilemma [67] and the achievement of sustainable development objectives [6]. The concept of energy equity, as the closeness of lower income populations generally located in rural areas of developing countries to energy access [65], is the responsibility of public institutions from each country. In order to attain the objectives framed within the previous three dimensions, an institutional alignment is required. Finally, all the activities and investments needed must be economically sustainable, at least, from the central management of the program. The quantification of regional and/or national rural electrification indexes becomes relevant only at an institutional level [68]. The criteria for the evaluation of this dimension are:

Institutional alignment (I-1): the organizational behavior of the program is assessed [69] as well as the institutional interactions and their efficiency in attaining the expected objectives [65]. This criterion is relevant for the evaluation of the design and provides intermediate results indirectly linked to the program objectives. 
Economic sustainability (I-2): the investment return mechanisms and their economic sustainability are evaluated within the context of each country [20]. This is significant for the evaluation of the design and provides intermediate results, as it only has an indirect influence on the achievement of the program objectives.

Program influence on REI(I-3): the impact of the program on rural electrification indexes (REI) is evaluated within the scope territories. This criterion is relevant for the evaluation of the design and provides final results directly related to the first objective (Section 2.1).

Energy equity (I-4): the prioritization and implementation decided upon during the program design are evaluated for poorer communities, irrespective of their location, ethnicity, social condition and scattering [70]. This criterion is relevant for the design and provides final results linked to the accomplishment of the first and second objectives of the program (Section 2.1).

\section{EVALUATION RESULTS FOR VENEZUELA}

Given the climate diversity in Venezuela, a selection matrix was developed to decide the "Sowing Light" program communities to be visited, having a wide overview of different climatic and ethnic conditions. In particular, 4 states were visited (Bolívar, Falcón, Mérida and Zulia), which group $35 \%$ of the implemented projects. Falcón and Zulia are located on the north-western coast of the country, having desert and semiarid climate conditions with average yearly temperatures exceeding $28^{\circ} \mathrm{C}$. Mérida is an Andean region where benefited communities are located at around 3,500 m.a.s.l., with an average yearly temperature of $12{ }^{\circ} \mathrm{C}$ and a highland climate. Finally, Bolívar is the largest state of the country $\left(240,528 \mathrm{~km}^{2}\right)$ and has a varied tropical monsoon climate.

As a result of collaboration between the Electrical Energy Ministry (Maracaibo, Venezuela) and the Universitat Politècnica de Catalunya (Barcelona, Spain), a technical inspection tool for the RET-based facilities and house surveys for program beneficiaries was conceived. Up to 22 communities were visited, carrying out 151 surveys in houses and 26 non-structured but wider interviews. The average duration of each survey was around 15-20 minutes, and it took 24 days to carry out the 151 surveys. The questionnaire was organized in 5 sections, focusing on the main aspects influencing projects sustainability: (1) rational use of energy and the environment; (2) demand and electricity consumption; (3) basic services; (4) education level and productive activities, and (5) perception of the service quality. In addition, consultations were held with the National Institute for Statistics of Venezuela [37]. Table 2 shows a detailed description of the communities visited. 
Table 2. Description of communities visited as well as surveys and interviews conducted

\begin{tabular}{|c|c|c|c|c|c|c|c|c|}
\hline State & Region & Community & $\begin{array}{c}\text { Total } \\
\text { houses }\end{array}$ & $\begin{array}{c}\text { Community } \\
\text { infrastructures }\end{array}$ & Population & Phases & Surveys & Interviews \\
\hline \multirow{6}{*}{ Bolívar } & \multirow{6}{*}{$\begin{array}{l}\text { La Gran } \\
\text { Sabana }\end{array}$} & $\begin{array}{c}\text { Santa Cruz de } \\
\text { Mapaurí }\end{array}$ & 80 & 4 & 400 & 1 & \multirow{6}{*}{24} & \multirow{6}{*}{11} \\
\hline & & $\begin{array}{c}\text { San Marcos de } \\
\text { Agua Fría }\end{array}$ & 15 & 2 & 80 & 1 & & \\
\hline & & $\begin{array}{c}\text { San Rafael de } \\
\text { Kamoirán } \\
\end{array}$ & 74 & 3 & 635 & 1 & & \\
\hline & & Uroy-Uaray & 48 & 3 & 260 & 1 & & \\
\hline & & Arapán & 13 & 3 & 35 & 2 & & \\
\hline & & Jaspe & 7 & 1 & 50 & 2 & & \\
\hline \multirow{5}{*}{ Falcón } & \multirow{3}{*}{ Paraguaná } & Jacuque & 8 & 2 & 99 & $\begin{array}{c}1,2 \& \\
3\end{array}$ & \multirow{5}{*}{49} & \multirow{5}{*}{3} \\
\hline & & La Macolla & 11 & 2 & 51 & $\begin{array}{c}1,2 \& \\
3\end{array}$ & & \\
\hline & & Punta Prudencio & 12 & 0 & 35 & 3 & & \\
\hline & \multirow{2}{*}{ Buchivacoa } & Matica de Yabo & 17 & 0 & 58 & 2 & & \\
\hline & & Los Arroyos & 12 & 2 & 41 & 3 & & \\
\hline \multirow{2}{*}{ Mérida } & \multirow{2}{*}{ Los Andes } & San Isidro & 22 & 0 & 75 & 2 & \multirow{2}{*}{11} & \multirow{2}{*}{6} \\
\hline & & Las González & 50 & 3 & 200 & $2 \& 3$ & & \\
\hline \multirow{9}{*}{ Zulia } & \multirow{9}{*}{ La Guajira } & Poloos & 24 & 2 & 151 & 3 & \multirow{9}{*}{67} & \multirow{9}{*}{6} \\
\hline & & Taparo & 15 & 1 & 88 & 3 & & \\
\hline & & Iramacira & 14 & 1 & 73 & 3 & & \\
\hline & & Wososopo & 26 & 1 & 152 & 3 & & \\
\hline & & Machuaiya & 17 & 1 & 99 & 3 & & \\
\hline & & Castilletes & 6 & 0 & 39 & 3 & & \\
\hline & & Cúsia & 36 & 2 & 168 & 3 & & \\
\hline & & Macuirrapa & 26 & 1 & 213 & 3 & & \\
\hline & & Punta Manglar & 16 & 1 & 91 & 3 & & \\
\hline \multicolumn{3}{|c|}{ Total } & 549 & 35 & 3093 & - & 151 & 26 \\
\hline
\end{tabular}

In the evaluation phase, specialized simulations were also used. HOMER v2.67. This software is widely used for off-grid RET-based electrification projects, both for the design and performance assessments [73]. Particularly, in this research, it is used to evaluate the performance of the electrification systems, considering real energy generation and real load profiles, based on resources (wind and solar) obtained from satellite databases, with an accuracy of 200m [5]. On the other hand, real load profiles are based on the 151 carried out load surveys. Therefore, real emissions factors $\left(\mathrm{Kg} \mathrm{CO}_{2 \text {-eq }} / \mathrm{kWhe}\right)$, derived from the diesel backup systems in Rural Hybrid Microgrids, was achieved. No emissions are considered for SHS and HWT, due to only operative and electricity related emissions are accounted. First, the generation performance is determined from the energy resources (wind and solar) [71]. The wind profiles are adjusted at the hub height, considering wind shearing data obtained from measurements taken at different heights by ENELVEN, the Electrical Energy company of Venezuela, over a period of more than 5 years. Next, the load profile is calculated from the surveys: the number of electrical appliances and usage hours. In all the communities, the peak load is reached in the $18-22 \mathrm{~h}$ period, as most of the electricity consumption comes from lighting, radio, TV and other appliances used at night.. 
In the following sections the accomplishment of each criterion is performed by means of some indicators, as has already been done in the literature for similar problems [72]. The indicators can be understood as the specific aspects to be evaluated from each criterion, depending on the socioeconomic characteristics of each country, as well as the availability and quality of data and the scope of the evaluation. Thus, the criteria have been prepared to be as easily replicable as possible in any other social, economic and technological context. However, some indicators should be appropriately adapted according to the institutional context and their foreseeable particular barriers.

\subsection{Environmental dimension}

In order to evaluate the environmental dimension of sustainability, the following information is consulted: (a) database of electrified communities by the AARE from the records of the Venezuelan National Institute for Statistics [37], (b) end-user surveys and (c) HOMER v2.67 simulations.

Communities fragile ecosystem (E-1): as an indicator to assess the accomplishment of this criterion, the rate between the number of projects implemented in communities located in fragile ecosystems and the total number of communities benefited by the program is considered. In this regard, 33.5\% of the projects have been installed within the 3 states (Amazonas, Bolívar and Zulia) having the largest number of environmentally protected areas [74], so the prioritisation of these communities is evident. Consequently, this criterion is positive for both the program design and intermediate results.

Technological change (E-2): before the installation of RET-based facilities, end-users from benefited communities used diesel generators to supply their energy requirements, operating up to 4 hours daily, with a capacity from 0.3 to $5.5 \mathrm{kVA}$,. The percentage of houses without such generators after the program implementation is used as an indicator to assess this criterion. The surveys were consulted to measure this indicator: $82.1 \%$ of end-users no longer use diesel generators,. Therefore, the technological change has led to the substitution of a polluting energy source and an improvement in the service quality [56]. Consequently, this criterion is positive both for the program design and intermediate results.

Emissions mitigation (E-3): this criterion is assessed through the emissions avoided by not using domestic diesel generators. For the calculation of this indicator, HOMER v2.67 is used. An emission factor of 0,006 and $0,267 \mathrm{Kg} \mathrm{CO}_{2 \text {-eq }} / \mathrm{kWhe}$ for $\mathrm{HMG}$ has been obtained under normal operation and one RET-based generation unit failure condition (N-1). Thus, related to the replaced domestic diesel generators, between 2005 and 2013, an estimated 5.2 GTon $\mathrm{CO}_{2} \mathrm{e}$ were avoided, saving around 2.1 million liters of fuel. Consequently, this criterion is positive in its final results.

As a result of the indicator assessment of each criterion, it can be stated that the "Sowing Light" program is environmentally sustainable. In particular, the three criteria show positive results and promote the accomplishment of the fifth objective of the program (Section 2.1).

\subsection{Technical dimension}

For the assessment of the technical sustainability dimension, and the corresponding criteria, the following information is consulted: (a) end-user surveys in order to determine domestic 
consumption levels, and (b) technical interviews to estimate equipment availability and failure frequency.

Adequacy (T-1): two indicators are used for the assessment of this criterion: (a) the difference between the average electricity consumption per house and the expected values of the system's design, and (b) the minimum consumption thresholds considered by the International Energy Agency [75]. The surveys are used to determine the electricity consumption. Thus, an energy consumption of $1.49 \mathrm{kWh} /$ day is estimated for SHS, 1.57 $\mathrm{kWh} /$ day for HWT, $1.60 \mathrm{kWh} /$ day for indigenous communities and $1.70 \mathrm{kWh} /$ day for non-indigenous communities, both with HMG. these values are almost three times higher than the minimum threshold defined by the IEA and do not exceed those considered for the design (Section 2.1). Consequently, the results for this criterion are positive.

Reliability (T-2): two indicators are used for this criterion: (a) the availability of electrification systems, and (b) the average time between equipment failures. The indicators are calculated from community visits and national databases [43]. During the 4.2 years that, on average, the HMG have been operating, the PV systems have never failed for long periods, while the average time between wind turbine failures is 2.5 years. On the other hand, 54\% of small wind turbines in HMG were inoperative. Hence, according to IEEE standards [76], the weighted average availability of the visited microgrids has been $81 \%$. In the case of SHS, $76 \%$ of the systems were available after an average operating time of 5.8 years. Lastly, the HWT were all available, not having presented failures in 4.2 years. Consequently, the results for this criterion are only satisfactory.

Considering that the system's design is adequate and reliability cannot be considered a big issue, within the technical dimension, the first objective of the program is achieved. In other words, the program is technically sustainable, although reliability aspects could be an issue in achieving long term results. Improvements are required in order to ensure the reliability of RET-based facilities, which corresponds to the implementation of the program.

\subsection{Socioeconomic dimension}

For the evaluation of the socioeconomic dimension of sustainability, the following information was considered: (a) end-user surveys and (b) data from the National Institute for Statistics and the Electrical Energy Ministry of Venezuela.

Management model (SE-1): two indicators are used for the assessment of this criterion: (a) the efficiency and training of COs and SMU technicians, and (b) the electricity service quality. The estimation is carried out by means of end-user surveys and technical interviews. In particular, in HMG houses, $60 \%$ of beneficiaries have a good opinion of COs efficiency and training. Regarding SMU technicians, 55\% of non-indigenous and $75 \%$ of the indigenous population identify a significant lack in their management activities. Indigenous communities feel less attention is paid to them, as their villages are highly dispersed and hard to access. On the other hand, between 2005 and 2013, 251 workshops were held, training a total 17,570 people in the adequate use of RET-based electrification systems and the detailed training of 1,705 COs [44]. Such efforts have led to the good evaluation of COs and RET-based facilities by end-users. However, $78 \%$ of beneficiaries consider that the electricity service quality has decreased during the last 
year, i.e. after at least 4 years of operation. Consequently, the results for this criterion are only satisfactory.

Rates sustainability (SE-2): two indicators are estimated from end-user surveys: (a) energy affordability for end-users, and (b) the electricity rate sufficient to cover the maintenance of community electrification systems. Currently, no electricity rate is established by the national government; the $\mathrm{CC}$ is in charge of defining the monthly fee to sustain COs activities, which at around $0.022 \$ / \mathrm{kWh}$ is absolutely affordable for beneficiaries. However, $68 \%$ of HMG users consider that the monthly fee should be a fixed value and cover all the annual operation and maintenance costs of microgrids. In spite of the affordability of electricity rates, they are not enough for the long-term maintenance of electrification systems without the technical and operational support of the national government. Consequently, the results for this criterion are negative.

Productivity (SE-3): the economic incomes of benefited families of the "Sowing Light" program and the opportunities for the development of productive activities after electricity access are considered as indicators. End-user surveys are used to estimate these values. Hence, an estimated $7 \%$ of the population has started new productive activities thanks to RET-based facilities. In indigenous communities from Gran Sabana (Bolívar), the implemented SHS have been used for the development of eco-tourist lodges. Simultaneously, the economic growth of indigenous communities is much lower than non-indigenous ones. Indeed, it can be observed how electricity access creates conditions for economic development, but how the end-users benefit is unequal and depends on previous socioeconomic conditions. Consequently, the results for this criterion are only satisfactory.

Beneficiaries per phase (SE-4): the indicator here used is the number of the beneficiary population at each phase of the program, which is defined from in-situ calculation and the Electrical Energy Ministry of the Country databases [48]. It has then been found that lower electrification costs for community services (phase 1) lead to a higher number of beneficiaries, thus rapidly alleviating basic service scarcities for a large population. In the later phases, the electrification costs were more expensive, having previously reached the education and health services. Consequently, the design of the program has been suitable and the results for this criterion are positive.

Education (SE-5): two indicators are assessed through end-user surveys and the Electrical Energy Ministry [48]: (a) the number of schools electrified, and (b) the beneficiaries' appraisal of education improvements. In the first phase of the program, 564 schools were electrified [44], and salary increases were used to motivate teachers to move to such isolated communities. In addition, surveys reveal that $31.1 \%$ of beneficiaries estimate that electrification within houses contributes to improving child education. Finally, 58.3\% of the electrified houses have bought a radio and/or a TV, while $24.3 \%$ directly or indirectly use Internet at schools and/or telecommunication centers. Consequently, this criterion shows positive results.

Health (SE-6): two indicators are assessed using end-user surveys and the Electrical Energy Ministry [48]: (a) the number of health centers electrified, and (b) the access to energy use in preventing unhealthy conditions. In the first phase of the program, 194 
health centers were electrified, as well as $20 \%$ of the water pumping and treatment systems installed in La Guajira and Paraguaná, where annual average temperatures are between $33{ }^{\circ} \mathrm{C}$ and $35^{\circ} \mathrm{C}$ in semi-arid climate conditions with very low rainfalls [77]. Moreover, surveys show that $48 \%$ and $64 \%$ of the houses in Paraguaná and La Guajira, respectively, have installed fridges. Thus, food and medicines can be refrigerated at an adequate temperature. In addition, electric light has substituted kerosene lamps, avoiding the emission of $\mathrm{CO}, \mathrm{NOx}$ and $\mathrm{SO} 2$ particles, thus improving respiration conditions inside the houses and reducing the probabilities of illnesses such as tuberculosis, asthma and cancer [78]. Consequently, this criterion shows positive results.

This is the most complex dimension of sustainability, as it comprises the largest number of objectives of the "Sowing Light" program. The criteria linked to the economic aspect (SE-1, SE2 and S-3) provide negative results: the program is not economically sustainable. However, the objectives of the program are precisely to create those favorable economic conditions and, to do so, some minimum education and health conditions are required [22].

\subsection{Institutional dimension}

For the evaluation of the institutional dimension of sustainability, data from the National Institute for Statistics and the Electrical Energy Ministry of Venezuela was considered. Using HOMER, the Cost of Electricity (COE) is obtained for each electrification technology in the "Sowing Light" program. This indicator is widely used all over the world when comparing different RET-based electrification projects.

Institutional alignment (I-1): the indicator for this criterion is the efficiency of the institutions involved in terms of their commitment to accomplishing the socioeconomic objectives of the program. In this regard, the social results have been globally positive. However, the economic results have only been satisfactory or negative. It should be highlighted that failures are concentrated in the RE and the AARE, both at a national level. Those failures should not be related to the design but to the implementation of the program. Consequently, the results for this criterion are only satisfactory.

Economic sustainability (I-2): the indicator considered is the Internal Rate of Return (IRR) of the program, including the $\mathrm{COE}$ and the fuel consumption costs of opportunity, as Venezuela is a country that exports refined products [58]. According to HOMER results COE is $1,605,0,273$ and 3,336 $\$ / \mathrm{kWh}$ for SHS, HMG and HWT, respectively. The IRR has been $20 \%$. The minimum IRR established in the country is $15 \%$ [79]. Therefore, the program design has been adequate. However, failures in implementation due to the lack of an appropriate institutional alignment are a handicap for the correct distribution of economic resources. Consequently, this criterion is positive for the design but only satisfactory in terms of the intermediate results of the implementation.

Program influence on REI (I-3): the indicator for this criterion is the Rural Electrification Index (REI). The calculation is made using information from the Electrical Energy Ministry [48] and the National Institute for Statistics [37]. The percentage of rural houses without electricity was reduced by between $39.3 \%$ and $85.1 \%$ through the development of "Sowing Light", according to village and house dispersion in the rural territories. In Zulia, the dispersion among indigenous villages and the scattering of house locations means that, despite having implemented three times more RET-based facilities than in 
Falcón, the improvement in the REI was 50\% lower. In Bolívar, where the largest amount of electrification systems was installed, the REI is still the lowest in the country, for the same reasons as Zulia. In global terms, the program has focused on those territories with a population density lower than 50 inhab. $/ \mathrm{km}^{2}$ and more than $2 \%$ of rural houses without electricity. Consequently, the lack of electricity access has decreased by $46 \%$ in such areas. The remainder corresponds to an extremely scattered population. This indicator evidences the effectiveness of the program design and the institutional approach when facing rural electrification. However, a higher effort is required for implementation in the most dispersed regions, so only satisfactory results are provided here, even in design and final results, as the design should be modified in order to attain significantly better results.

Energy equity (I-4): the indicator for this criterion evaluates the differences between the urban and rural electrification rates, or between rural indigenous communities, benefited by the "Sowing Light" program, and non-indigenous urban territories. The tools used are databases from the Electrical Energy Ministry [48] and the National Institute for Statistics [37]. In 2001, the territories with the lowest population density among the four visited had REI values under 80\% [80]. At that time, indigenous communities represented $75 \%$ of the houses without electricity in Bolívar and Zulia. Consequently, $71.5 \%$ of the houses from indigenous ethnic groups of Zulia (Wayuú and Barí) were electrified with renewable energy. This has had an influence on improving energy equity, shown by the reduction in REI differences between urban and rural areas, which decreased by $25 \%$ in Zulia and 43\% in Bolívar. Meanwhile, in states without an indigenous population, such as Falcón and Mérida, the reductions were $70 \%$ and $80 \%$, respectively. The differences in those values are caused by the fact that the non-indigenous population tends to live in more populated and less dispersed villages. The results provided by this criterion show a significant improvement in energy equity thanks to RET-based facilities, both in indigenous and non-indigenous communities, especially in the poorer territories of the country. Consequently, this criterion is positive both for the program design and final results.

The above mentioned criteria show that failures happen not in the design but in the program implementation, particularly in the institutional alignment (I-1). Although a higher proportion of renewable energy is required in the rural electrification technology matrix, considering previously excluded communities as one of the main objectives of the program globally transforms the institutional criteria into positive results. Therefore, the program is institutionally sustainable. Table 3 summarizes all the results. 
Table 3. Results by sustainability dimension for the design and implementation of the "Sowing Light" program

\begin{tabular}{|c|c|c|c|c|}
\hline \multirow{2}{*}{ Dimension } & \multirow{2}{*}{ Criterion } & \multirow{2}{*}{$\begin{array}{c}\text { Design } \\
\text { evaluation } \\
\text { results* }\end{array}$} & \multicolumn{2}{|c|}{$\begin{array}{c}\text { Implementation } \\
\text { evaluation }\end{array}$} \\
\hline & & & $\begin{array}{c}\text { Intermediate } \\
\text { results* }\end{array}$ & $\begin{array}{l}\text { Final } \\
\text { results* }\end{array}$ \\
\hline \multirow{3}{*}{ Environmental } & Communities fragile ecosystem (E-1) & + & + & \\
\hline & Technological change (E-2) & + & + & \\
\hline & Emissions mitigation (E-3) & & & + \\
\hline \multirow{2}{*}{ Technical } & Adequacy (T-1) & + & & + \\
\hline & Reliability (T-2) & & & \pm \\
\hline \multirow{6}{*}{ Socioeconomic } & Management model (SE-1) & \pm & \pm & \\
\hline & Rates sustainability (SE-2) & - & - & \\
\hline & Productivity (SE-3) & \pm & & \pm \\
\hline & Beneficiaries per phase (SE-4) & + & + & \\
\hline & Education (SE-5) & + & & + \\
\hline & Health (SE-6) & + & & + \\
\hline \multirow{4}{*}{ Institutional } & Institutional alignment (I-1) & + & \pm & \\
\hline & Economic sustainability (I-2) & + & \pm & \\
\hline & Program influence on REI (I-3) & \pm & & \pm \\
\hline & Energy equity (I-4) & + & & + \\
\hline
\end{tabular}

* Positive (+); Satisfactory ( \pm ); Negative (-)

\section{DISCUSSION ABOUT THE PROGRAM DESIGN AND IMPLEMENTATION}

Regarding the program design, the final results show consistency with the objectives conceived by the AARE (Section 2.1) according to the RE indications, which is especially demonstrated by the improvements in education (SE-5) and health (SE-6) conditions. In this regard, the institutional alignment (I-1) is positive. Concerning the tools used for the evaluation of the environmental dimension, it can be observed how the installation of RET-based facilities in communities located in fragile ecosystems (E-1) has been prioritized. Prioritization has been effective, since the electrification systems deployed have promoted a technological change (E-2). In order to accomplish this change, the adequate design of RET-based facilities (T-1) has been fundamental, both for exceeding the globally estimated minimum thresholds and for its adequacy to the energy requirements of the local population, as proved through end-user surveys. Finally, the program phases when dealing with communities and houses having different needs (SE-4) respond to a design aiming to prioritize education and health and then provide higher energy access levels (I-3), thus improving the energy equity in poorer areas (I-4). This has been possible thanks to a design which bases economic sustainability on fossil fuel savings (I-2).

Regarding the intermediate results, greater needs for improvement have been found. The two elements requiring most attention in order to ensure medium and long-term sustainability are: the management model (SE-1) and the institutional alignment (I-1). As mentioned previously, both elements are directly linked to other objectives and results of the program. Therefore, their improvement will have a very positive impact on other indicators and criteria needing to be enhanced. Electricity rates (SE-2), although affordable, are not economically sustainable in the long term (I-2), as communities are dependent on government subsidies for the maintenance activities of the AARE, through SMU technicians. Although in the short term the electrification systems have been operational (on average for 5 years), this model must be improved in order to 
ensure medium and long-term sustainability. However, both factors of sustainability rates (affordability and financial sustainability in the medium and long term) are equally important within the framework of the proposed set of dimensions for the evaluation of sustainable development in rural electrification programs. The implementation in progressive phases (SE-4) has been positive, as the technological change (E-2) has gradually been introduced, which is fundamental in communities located in fragile ecosystems (E-1).

Regarding the final results of the program implementation, the reduction in pollution emissions (E-3) is probably the most noteworthy positive result. End-users' satisfaction is motivated since the beneficiaries can meet their energy requirements (T-1, SE-5 and SE-6), thus promoting energy equity (I-4), which is the final result directly related to the program objective. However, there are significant elements to be improved in terms of final results. For example, the reliability of RETbased facilities (T-2) is influenced by the appropriate development of maintenance activities, in addition to the system's adequacy (T-1). In this regard, reliability is related to the management model (SE-1) and the institutional alignment (I-1), which only show satisfactory results in the intermediate results of the program implementation. Simultaneously, the socioeconomic dimension is the most complex one, since significant social improvements are evident (SE-4, SE5 and SE-6) while economic aspects still have to be improved (SE-1, SE-2 and SE-3) in most of the communities benefited. Indeed, an unequal productivity development (SE-3) has been observed, directly related to the prior socioeconomic status of each village. This aspect should have been considered in the program design or, otherwise, during the implementation, although limitations in the institutional alignment (I-1) have been a handicap. In fact, where the coordinated participation of several institutions did occur, microcredits were granted to end-users to improve productivity levels. Likewise, the economic sustainability of the program (I-2) is threatened by these failures in the institutional alignment, since the benefits of fossil fuel savings do not have an impact on the improvement of system maintenance. Finally, the results show how expanding electrification access is becoming increasingly more complicated, since the remaining houses without electricity are progressively more dispersed. In such areas only RET-based facilities can be used, so the participation of renewable technologies in the energy matrix must be increased in order to improve the REI (I-3).

Usually, the implementation of a rural electrification program using off-grid RET-based projects is considered when the initial costs are lower than grid extension. However, through a comparison of the obtained results from the proposed methodology application on the "Sowing Light" program, in Venezuela, yields to some intermediate results useful to compare the four dimensions between both strategies in Venezuela: environmental, institutional (financial) and technical and socioeconomic, in accordance with the methodology proposed in the paper.

The environmental and financial aspects correspond to the environmental and institutional dimensions. In order to compare the Sowing Light program and grid extension in terms of both dimensions, two key factors are analysed: Cost of Energy (COE, $\$ / \mathrm{kWh})$ and Emission Factors (Kg CO2-eq/kWhe), which are widely used all over the world when comparing electrification projects. The results for off-grid RET-based electrification (Sowing Light program) are obtained from the intermediate results. Both indicators are calculated from HOMER v2.67 software simulations. An emission factor of 0.006 and $0.267 \mathrm{Kg} \mathrm{CO} 2-\mathrm{eq} / \mathrm{kWhe}$ for $\mathrm{HMG}$ is obtained under normal operation and an (N-1) failure condition. The COE is also determined from HOMER results: $1.605,0.273$ and $3.336 \$ / \mathrm{kWh}$ for SHS, HMG and HWT, respectively. On their behalf, grid extension results are obtained from the literature [44] and previous studies from the own 
authors [81]. The COE estimations include the fuel consumption costs of opportunity, as Venezuela is a country that exports refined products. It must be highlighted that the oil producer condition of Venezuela enables a wide fuel-based generation at a low cost, using national refined products from Venezuelan refineries. However, their high cost of opportunity turns RET-based rural electrification economically feasible. On the other hand, the emission factor is determined from the north-western Venezuela energy matrix, where fossil fuels share is almost $50 \%$ of the total generated electricity. The new results are shown in a new Table 4, at the end of Section 5 (discussion section). This table includes average and summarized factors for the environmental and institutional (financial) comparison between conventional and off-grid RET-based electrification.

Table 4. Cost of Energy and Emission factors for the comparison between conventional grid extension and RET-based rural electrification projects in Venezuela

\begin{tabular}{|c|c|c|c|}
\hline \multirow{2}{*}{\multicolumn{2}{|c|}{ Electrification Technologies }} & \multicolumn{2}{|c|}{ Comparative Factors } \\
\hline & & $\mathrm{Kg} \mathrm{CO}$ 2-eq $/ \mathrm{kWhe}$ & COE $(\$ / \mathbf{k W h})$ \\
\hline \multicolumn{2}{|c|}{ Grid extension $^{1}$} & 0,627 & $0,255^{3}$ \\
\hline \multirow{3}{*}{$\begin{array}{c}\text { RET-based electrification in } \\
\text { Venezuela }\end{array}$} & SHS & 0 & 1,605 \\
\hline & $\mathrm{HMG}\left(\mathrm{N}-1^{2}\right)$ & $0,006(0,267)$ & 0,273 \\
\hline & HWT & 0 & 3,336 \\
\hline
\end{tabular}

1) Values considered correspond to grid extension in north-western Venezuela, where most of the analysed systems were installed. ${ }^{2)} \mathrm{N}-1$ condition correspond to operations under one RET-based generation element in the microgrid has been failed. ${ }^{3)}$ Cost based on north-western Venezuela electrical grid according to López-González [81].

Although generally the hydroelectric generation is around 65\% in Venezuela [5], in the northwestern region of Venezuela only $50 \%$ of electricity comes from the hydro source, due to 1,100 $\mathrm{km}$ distance from the large hydroelectric power plants. In this region, thermoelectric generation represents $50 \%$ of the supply, so the emission factor is significantly high and RET-based technologies comparatively become an extremely low emissions option. Additionally, thermoelectric power plants work with diesel coming from Venezuelan refineries located in Falcón and Zulia states. Both the environmental and financial (institutional) issues are influenced by this particular situation where the $\mathrm{COE}$ of conventional grid extension is almost as high as for HMG. Consequently, RET-based rural electrification in oil producer countries, like Venezuela, reach competitive levels when considering the cost of opportunity caused when consuming fuel instead of selling it to the international market.

Regarding the technical dimension, reliability is a key issue to compare RET-based projects and conventional grid extension; and particularly the Mean Time Between Failures (MTBF) and the Mean Time To Repair (MTTR) [7]. It must be noted that rural distribution grids are usually long and poorly maintained, so failure rate frequencies are high and MTTR long. In RET-based projects, these values may vary between rural areas, but according to the surveys carried out in electrified houses and the sizing of projects, both MTBF and MTTR are lower than for neighbour communities electrified through grid extension. Regarding the socioeconomic dimension, the impact on education and health is higher in RET-based communities than in conventional grid extension ones. This is because RET electrified communities generally have a lower development baseline than grid extension ones. In fact, rural settlements reached through RET-based 
technologies have less than 40 (or even 20) houses and correspond to indigenous or frontier communities where no previous electricity usages were extended. In contrast, communities benefited from the grid usually have more than 40 houses, and most of them previously have domestic diesel systems

\section{Conclusion}

In this work, a methodology for the evaluation of rural electrification programs with a management perspective and a formative purpose has been proposed. The evaluation is carried out from 4 sustainability dimensions, assessed by means of 15 criteria sufficiently robust to be replicated according to the institutional context and their foreseeable particular barriers in social, economic and political aspects. In this regard, this methodological approach is clearly distinguishable from previous evaluations that are subject to a single dimension of sustainability and/or to a local, regional or national level for a specific program stage (design or implementation). The application of the proposed methodology to the "Sowing Light" program shows its short and medium term sustainability, since the design is suitable for positive final results in terms of improving education and health within benefited communities. These results were obtained thanks to the distinction between dimensions, stages and territory levels, which facilitates the diagnosis of the causes of success and failure, thus helping decision-makers in charge of the program. The implementation mechanisms assessed by means of the intermediate results, show the need for improvements; particularly regarding the institutional alignment and the economic sustainability. In this regard, rural electrification programs must be accompanied by more effective policies when addressing the productivity development of each community, especially in indigenous areas. Thus, the results allow the important issues to be distinguished from the circumstantial ones. Failures in implementation mechanisms, such as electricity rates, management and institutional alignment, are surmountable by taking the appropriate corrective measures, which have been identified from the application of the formative evaluation with a management perspective.

On the other hand, a four-dimension comparison has been made between RET-based rural electrification projects and the conventional grid extension. This comparison is particularly remarkable for the technical and institutional dimensions. First, in the technical dimension, a RET-based project could be more reliable than conventional electrification, since the second option is usually made up of long distribution lines, and failure rates are proportional to their extension. Regarding the institutional dimension, the cost of generated electricity in conventional systems is almost as high as RET-based projects, particularly considering the cost of opportunity of fuel in oil producer countries, like northern African and middle-east ones, where such cost must be considered as a revenue. Both issues have an impact on the environmental dimension in terms of the emissions factor reduction in comparison to grid extension and domestic diesel systems. Finally, the socioeconomic dimension depends on previous community health, education and economic development.

In short, the proposed methodology allows the identification, with a formative purpose, of the sustainability dimensions and criteria with greater chances of improvement from a management perspective, both in the design and implementation of the program. Formative evaluations can lead to continual improvement in rural electrification programs, under the framework of more favorable energy policies to achieve the sustainable development goals defined by the United Nations for the year 2030 [6]. The proposed management perspective makes possible to identify the institutional barriers and their particular impact on the design and/or implementation of the 
program, as well as the impact on the other three sustainability dimensions. Lastly, it should be noted that such an approach can be used to evaluate programs using other, but widely used, technologies for electricity supply such as diesel generators, micro-hydro power plants or PVdiesel hybrid systems.

\section{ACKNOWLEDGMENTS}

This research was funded by the Spanish Ministry of Science and Innovation (project ENE 201567253-R) and the Centre for Cooperation Development (CCD) of the Universitat Politècnica de Catalunya Barcelona TECH (UPC). It has been possible thanks to the collaboration of engineers and technicians of the "Sowing Light" program (Fundelec), the Ministry of Electrical Power of Venezuela and communal councils of electrified communities in Bolivar, Falcón, Mérida and Zulia states in the Bolivarian Republic of Venezuela.

\section{REFERENCES}

[1] REN21. Renewables 2016: Global Status Report. Paris: 2016.

[2] Doll CNH, Pachauri S. Estimating rural populations without access to electricity in developing countries through night-time light satellite imagery. Energy Policy 2010;38:5661-70. doi:10.1016/j.enpol.2010.05.014.

[3] Cader C, Blechinger P, Bertheau P. Electrification Planning with Focus on Hybrid Minigrids - A Comprehensive Modelling Approach for the Global South. Energy Procedia 2016;99:269-76. doi:10.1016/j.egypro.2016.10.116.

[4] IRENA. Renewable capacity statistics 2016. Abu Dhabi: 2017.

[5] IRENA. 2016 a Record Year for Renewables, Latest IRENA Data Reveals. Renew Energy Capacit Stat 20172017.

http://www.irena.org/News/Description.aspx?NType=A\&mnu=cat\&PriMenuID=16\&Ca tID=84\&News_ID=1486 (accessed April 26, 2017).

[6] United Nations. Transforming our world: The 2030 agenda for sustainable development. 2015. doi:10.1007/s13398-014-0173-7.2.

[7] Jimenez R. Barriers to electrification in Latin America: Income, location, and economic development. Energy Strateg Rev 2017;15:9-18. doi:10.1016/j.esr.2016.11.001.

[8] International Energy Agency IEA. Table 4: Electricity access in 2010 - Latin America. World Energy Outlook 20122012.

www.iea.org/media/.../WEO2012Electricitydatabase_WEB.xlsx (accessed January 16, 2017).

[9] MINEM. Plan Nacional De Electrificacion Rural ( Pner ) Periodo 2013 - 2022. Lima: 2012.

[10] Pereira MG, Freitas MAV, da Silva NF. Rural electrification and energy poverty: Empirical evidences from Brazil. Renew Sustain Energy Rev 2010;14:1229-40. doi:10.1016/j.rser.2009.12.013.

[11] Slough T, Urpelainen J, Yang J. Light for all? Evaluating Brazil's rural electrification progress, 2000-2010. Energy Policy 2015;86:315-27. doi:10.1016/j.enpol.2015.07.001.

[12] Peredo Echazú R, Jiménez Rivera H, Gonzáles Flores JM. Plan de Universalización Bolivia con Energía 2010-2025 2010:1-28. 
[13] MEER. FERUM - Ministerio de Electricidad y Energía Renovable. Fondo Electrif Rural Urbano y Marg 2017. http://www.energia.gob.ec/ferum/ (accessed January 23, 2017).

[14] Tech4CDM. La Electrificación Rural en ECUADOR. Quito: 2009.

[15] López-González A, Domenech B, Gómez-Hernández D, Ferrer-Martí L. Renewable microgrid projects for autonomous small-scale electrification in Andean countries. Renew Sustain Energy Rev 2017;79:1255-65. doi:10.1016/j.rser.2017.05.203.

[16] Kyte R. Learning from the success stories. Sustainable energy for all is possible through sharing good examples. World Energy Focus 2017:3-4.

[17] Pereira MG, Sena JA, Freitas MAV, Silva NF Da. Evaluation of the impact of access to electricity: A comparative analysis of South Africa, China, India and Brazil. Renew Sustain Energy Rev 2011;15:1427-41. doi:10.1016/j.rser.2010.11.005.

[18] Terrapon-Pfaff J, Dienst C, König J, Ortiz W. A cross-sectional review: Impacts and sustainability of small-scale renewable energy projects in developing countries. Renew Sustain Energy Rev 2014;40:1-10. doi:10.1016/j.rser.2014.07.161.

[19] Mainali B, Pachauri S, Rao ND, Silveira S. Assessing rural energy sustainability in developing countries. Energy Sustain Dev 2014;19:15-28. doi:10.1016/j.esd.2014.01.008.

[20] Urmee T, Harries D, Holtorf H-G. Success and Sustainability Criteria and Issues for SHS Programmes. Photovoltaics Rural Electrif. Dev. Ctries. A Road Map, Cham: Springer International Publishing; 2016, p. 79-107. doi:10.1007/978-3-319-03789-9_4.

[21] van de Walle D, Ravallion M, Mendiratta V, Koolwal G. Long-term impacts of household electrification in rural India. 2013. doi:10.1093/wber/lhv057.

[22] Mason M. Rural electrification: a review of World Bank and USAID financed projects. Washington, D.C.: 1990.

[23] Zomers A. The challenge of rural electrification. Energy Sustain Dev 2003;7:69-76. doi:10.1016/S0973-0826(08)60349-X.

[24] Ilskog E. Indicators for assessment of rural electrification-An approach for the comparison of apples and pears. Energy Policy 2008;36:2665-73. doi:10.1016/j.enpol.2008.03.023.

[25] Yadoo A, Cruickshank H. The role for low carbon electrification technologies in poverty reduction and climate change strategies: A focus on renewable energy mini-grids with case studies in Nepal, Peru and Kenya. Energy Policy 2012;42:591-602. doi:10.1016/j.enpol.2011.12.029.

[26] Lillo P, Ferrer-Martí L, Fernández-Baldor Á, Ramírez B. A new integral management model and evaluation method to enhance sustainability of renewable energy projects for energy and sanitation services. Energy Sustain Dev 2015;29:1-12. doi:10.1016/j.esd.2015.08.003.

[27] Merino M. Fundamentos de evaluación de políticas públicas. Madrid: 2010. doi:10.1073/pnas.0703993104.

[28] Eleanor C. Differing perspectives of evaluation. New Dir Progr Eval 1978;2:1-18.

[29] SEforAll. SUSTAINABLE ENERGY FOR ALL STRATEGIC FRAMEWORK FOR RESULTS | 2016-21. Vienna: 2016. 
[30] Santos SP, Amado CAF, Rosado JR. Formative evaluation of electricity distribution utilities using data envelopment analysis. J Oper Res Soc 2011;62:1298-319.

[31] Khembo F, Chapman S. A formative evaluation of the recovery public works programme in Blantyre City, Malawi. Eval Program Plann 2017;61:8-21. doi:10.1016/j.evalprogplan.2016.10.012.

[32] Wholey JS. Formative and Summative Evaluation: Related Issues in Performance Measurement. Evalutation Pract 1996;17:145-9. doi:10.1177/109821409601700206.

[33] Henry GT, Smith AA, Kershaw DC, Zulli RA. Formative evaluation: Estimating preliminary outcomes and testing rival explanations. Am J Eval 2013;34:465-85. doi:10.1177/1098214013502577.

[34] Ilskog E, Kjellström B. And then they lived sustainably ever after?-Assessment of rural electrification cases by means of indicators. Energy Policy 2008;36:2674-84. doi:10.1016/j.enpol.2008.03.022.

[35] Heuberger R. CDM Projects under the Kyoto Protocol of the UNFCCC : A Methodology for Sustainable Development Assessment and an Application in South Africa. Swiss Federal Institute of Technology (ETH), 2003.

[36] Massabié G. Venezuela: A Petro-State Using Renewable Energies: A Contribution to the Global Debate about New Renewable Energies for Electricity Generation. 1st Editio. Wiesbaden: VS Verlag für Sozialwissenschaften; 2008.

[37] Instituto Nacional de Estadística. Censo 2011 Redatam 2017. http://www.redatam.ine.gob.ve/Censo2011/index.html (accessed March 24, 2017).

[38] Instituto Nacional de Estadistica. Síntesis Estadística. Síntesis Estadística 2013:1. http://www.ine.gov.ve/index.php?option=com_content\&view=category\&layout=blog\&i $\mathrm{d}=116 \&$ Itemid $=10$ (accessed January 10, 2017).

[39] Haanyika CM. Rural electrification in Zambia: A policy and institutional analysis. Energy Policy 2008;36:1044-58. doi:10.1016/j.enpol.2007.10.031.

[40] Fundelec. Reseña Histórica: Fundelec 2015:1. http://www.fundelec.gob.ve/?page_id=310 (accessed January 10, 2017).

[41] López-González A, Domenech B, Ferrer-Martí L. Rural electrification with renewable energy and sustainable development in isolated, indigenous and frontier communities of Venezuela. Energy Soc. 1st Int. Conf. Energy Res. Soc. Sci., Sitges: Energy Research and Social Science; 2017.

[42] Pérez LA. The Guajira (Wayuu): Time, Space and Circumstances. Cuad Venez Sociol 2006;15:403-26.

[43] Fundelec. Sembrando Luz: Promoviendo las Energías Renovables en Zonas Aisladas, Indígenas y Fronterizas del país 2012:32.

[44] MPPEE. Anuario estadístico 2013: Sector Eléctrico Venezolano 2013:83. doi:201108DC35.

[45] IRENA. Investment Oportunities in Latin América. Glob Atlas Renew Energy 2017. https://irena.masdar.ac.ae/GIS/?map=2012 (accessed May 19, 2017).

[46] López-González A, Domenech B, Gómez-Hernández D, Ferrer-Martí L. Renewable microgrid projects for autonomous small-scale electrification in Andean countries. 
Renew Sustain Energy Rev 2017;79:1255-65. doi:10.1016/j.rser.2017.05.203.

[47] De Pablos K. Solar and wind electricity sources. Alternative, clean and renewable energy. Orinoco Magna Reserv 2014:21-4.

[48] MPPEE. Plan de Desarrollo del Sistema Electrico Nacional 2013-2019. Caracas: 2013.

[49] Jami AA, Walsh PR. From consultation to collaboration: A participatory framework for positive community engagement with wind energy projects in Ontario, Canada. Energy Res Soc Sci 2017;27:14-24. doi:10.1016/j.erss.2017.02.007.

[50] Arnstein SR. A Ladder Of Citizen Participation. J Am Inst Plann 1969;35:216-24. doi:10.1080/01944366908977225.

[51] Vanhulst J, Beling AE. Buen vivir: Emergent discourse within or beyond sustainable development? Ecol Econ 2014;101:54-63. doi:10.1016/j.ecolecon.2014.02.017.

[52] Vivas-Escobar N. Programa Sembrando Luz: 9 años de inclusión social de la mano de las energías renovables. In: Organización Latinoamericana de Energía, editor. IV Semin. Latinoam. y del Caribe Electr. - ELEC 2014, Lima: Organización Latinoamericana de Energía; 2014, p. 27.

[53] Trochim WMK, Linton R. Conceptualization for planning and evaluation. Eval Program Plann 1986;9:289-308.

[54] Schoster B, Altpeter M, Meier A, Callahan LF. Methodological Tips for Overcoming Formative Evaluation Challenges. Health Promot Pract 2012;13:198-203. doi: $10.1177 / 1524839910384060$.

[55] Brown KG, Brown KG, Gerhardt MW, Gerhardt MW. Formative Evaluation: an Integrative Practice Model and Case Study. Pers Psychol 2002;55:951-83.

[56] Sorrell S. Energy substitution, technical change and rebound effects. Energies 2014;7:2850-73. doi:10.3390/en7052850.

[57] Strachan N, Farrell A. Emissions from distributed vs. centralized generation: The importance of system performance. Energy Policy 2006;34:2677-89. doi:10.1016/j.enpol.2005.03.015.

[58] Pachauri S. Reaching an international consensus on defining modern energy access. Curr Opin Environ Sustain 2011;3:235-40. doi:10.1016/j.cosust.2011.07.005.

[59] Sovacool BK. A qualitative factor analysis of renewable energy and Sustainable Energy for All (SE4ALL) in the Asia-Pacific. Energy Policy 2013;59:393-403. doi:10.1016/j.enpol.2013.03.051.

[60] Billinton R. Reliability Evaluation of Power Systems. vol. 30. 2nd ed. New York: Plenum Press; 1996. doi:10.1049/ep.1984.0253.

[61] Brundtland GH. Our Common Future: Report of the World Commission on Environment and Development. Med Confl Surviv 1987;4:300. doi:10.1080/07488008808408783.

[62] Haanyika CM. Rural electrification policy and institutional linkages. Energy Policy 2006;34:2977-93. doi:10.1016/j.enpol.2005.05.008.

[63] Modi V, McDade S, Lallement D, Saghir J. Energy Services for the Millennium Development Goals. 2005.

[64] Gollwitzer L, Ockwell D, Muok B, Ely A, Ahlborg H. Rethinking the sustainability and 
institutional governance of electricity access and mini-grids: Electricity as a common pool resource. Energy Res Soc Sci 2018;39:152-61. doi:10.1016/j.erss.2017.10.033.

[65] Haanyika CM. Rural electrification in Zambia: A policy and institutional analysis. Energy Policy 2008;36:1044-58. doi:10.1016/j.enpol.2007.10.031.

[66] Mawhood R, Gross R. Institutional barriers to a "perfect" policy: A case study of the Senegalese Rural Electrification Plan. Energy Policy 2014;73:480-90. doi:10.1016/j.enpol.2014.05.047.

[67] World Energy Council. World Energy Trilemma 2016 Defining Measures To Accelarate the Energy Transition. London: 2016.

[68] van Ruijven BJ, Schers J, van Vuuren DP. Model-based scenarios for rural electrification in developing countries. Energy 2012;38:386-97. doi:10.1016/j.energy.2011.11.037.

[69] Bekker B, Eberhard A, Gaunt T, Marquard A. South Africa's rapid electrification programme: Policy, institutional, planning, financing and technical innovations. Energy Policy 2008;36:3115-27. doi:10.1016/j.enpol.2008.04.014.

[70] Wilson E. Energy equity: can the UN Sustainable Energy for All initiative make a difference? | International Institute for Environment and Development. Int Inst Environ Dev 2012:1. https://www.iied.org/energy-equity-can-un-sustainable-energy-for-allinitiative-make-difference (accessed April 21, 2017).

[71] IRENA. Global Atlas Gallery 3.0 2017. https://irena.masdar.ac.ae/gallery/\#gallery (accessed June 19, 2017).

[72] Pokorny, Benno; Sabogal, Cesar; De Camino R. Metodologías para evaluar la aplicación de criterios e indicadores en el manejo forestal de bosques tropicales en América Latina. Recur Nat y Ambient 2001;36:14-9.

[73] Sen R, Bhattacharyya SC. Off-grid electricity generation with renewable energy technologies inIndia: An application of HOMER. Renew Energy 2014;62:388-98. doi:10.1016/j.renene.2013.07.028.

[74] Isabel M, Viera S, General D, Vigilancia D, Ambiental C, Ambiente PP. Las ABRAE versus las áreas protegidas en Venezuela. Rev COPÉRNICO 2014;10:27-39.

[75] International Energy Agency. Africa Energy Outlook. A focus on the energy prospects in sub-Saharan Africa. 2014.

doi:https://www.iea.org/publications/freepublications/publication/africa-energyoutlook.html.

[76] IEEE. IEEE Guide for Electric Power Distribution Reliability Indices (IEEE Std $1366^{\mathrm{TM}}$ 2012). vol. 1997. The Institute of Electrical and Electronics Engineers; 2012. doi:10.1109/IEEESTD.2012.6209381.

[77] Instituto Nacional de Estadística. XIV Censo Poblacional de Población y Vivienda. Resultados por Entidad Federal y Municipio del Estado Falcón. Caracas: 2014.

[78] Lam NL, Smith KR, Gauthier A, Bates MN. Kerosene: a review of household uses and their hazards in low- and middle-income countries. J Toxicol Environ Health B Crit Rev 2012;15:396-432. doi:10.1080/10937404.2012.710134.

[79] Domínguez L. Evaluaciones económicas y ajustes de precios a contratos de PDVSA: Refinería El Palito. Bárbula: 2014. 
[80] Censos de población y vivienda n.d.

http://www.ine.gov.ve/index.php?option=com_content\&view=category\&id=95\&Itemid =9\# (accessed February 14, 2017).

[81] López-González A. Escenarios de ahorro de recursos energéticos en Venezuela empleando gas y energías renovables. III Jorn. Nac. Efic. Energética 2014, Caracas: Ministerio del Poder Popular para la Energía Eléctrica; 2014, p. 1-12. 